\title{
A emergência decolonial: Ciências Sociais e a crise epistêmica da "Modernidade"
}

Carlos Eduardo Bao'

Resumo: O objetivo desse trabalho é explanar a gênese colonial do mundo moderno e da estrutura de poder/saber gerada em seu âmago, indicando como os saberes originários das Ciências Sociais são eurocêntricos e como a emergência decolonial almeja desnaturalizar os saberes eurocêntricos desse campo de conhecimento. Ao fim, sugere a "desobediência epistêmica” como ação capaz de promover tal desnaturalização epistemológica.

Palavras-chave: Modernidade/Colonialidade; Ciências Sociais; Decolonial.

\section{The decolonial emergency: social sciences and the epistemic crisis of "Modertnity"}

\begin{abstract}
This work's objective is to explain the colonial genesis of the modern world and the power/knowledge structure generated a tis core, indicating how the knowledge originating from de Social Sciences are eurocentric and how the decolonial emergency aims to denaturalize the eurocentric knowledge of this field of knowledge. In the end, it suggests "epistemic disobedience" as na action capable of promoting such epistemological denaturalization.
\end{abstract}

Key-words: Modernity/Coloniatily; Social Sciences; Decolonial.

Doutor em Sociologia Política. Professor substituto na graduação em Ciências Sociais, UNIOESTE/Toledo. E-mail: carloseduardobao@hotmail.com 


\section{Introdução: modernidade/colonialidade e pensamento eurocêntrico}

A chamada "crise epistêmica" é o carcoma da "Modernidade" e do pensamento eurocêntrico. A crise, nesse caso, é fruto da emergência de sujeitos silenciados/as pelo monólogo universalista da razão ilustrada. Milhões de mulheres, povos originários, povos outrora escravizados, trabalhadores e trabalhadoras pauperizados/as que passaram a conquistar espaços na esfera pública e em campos reservados às elites sociais, tais como a universidade, a política e setores da burocracia estatal, entre outros.

O objetivo desse trabalho é explanar a gênese colonial do mundo moderno e da estrutura de poder/saber gerada em seu âmago, indicando como os saberes originários das Ciências Sociais são eurocêntricos e como a emergência decolonial almeja desnaturalizar os saberes eurocêntricos desse amplo campo de conhecimento, ampliando, assim, seus horizontes conceituais.

Uma das características axiais do pensamento eurocêntrico é o dualismo engendrado em seu modus operandi, por meio do qual se fundamenta boa parte da cosmologia ocidental. A separação ontológica entre o res cogitans, a "mente", e o corpo, a "máquina", deduzida por Descartes (1991) vincula-se a uma longa tradição de pensamento originada com a "síntese" platônica acerca da antinomia entre o Ser como devir (heraclitiano) ou o Ser como permanência (parmenidiano), respectivamente, "mundo sensível” e "mundo inteligível” (PLATÃO, 2002).

Segundo Lander (2005), a cosmologia ocidental é marcada pelas seguintes fragmentações ontológicas: a) separação religiosa, judaico-cristã, entre Deus (o sagrado), o homem (o humano) e a natureza; b) (a partir da Ilustração francesa): ruptura ontológica entre corpo e mente, razão e mundo; c) separação entre sujeito e objeto; e d) separação entre tempo e espaço. Tais abstrações pavimentam "uma fissura ontológica entre a razão e o mundo [...] base de um conhecimento descorporizado e descontextualizado [...] que pretende ser des-subjetivado (isto é, objetivo) e universal" (LANDER, 2005, p. 23-26).

Tais separações proporcionaram o surgimento de um "sujeito atópico" supostamente capaz de praticar um discurso de conhecimento Universal. Nessa arquitetura de poder/saber, a Europa ocidental, autodeclarada herdeira da tradição da filosofia mediterrânea clássica, passou a ocupar o lugar do sujeito emissor do Conhecimento via secularização do pensamento e canonização da Academia (cosmologia ocidental) como lugar da Verdade.

Entre os resultados desse processo está o surgimento do imaginário de uma civilização europeia supostamente superior, avançada, na vanguarda da origem e da culminação do processo histórico em relação às demais civilizações presentes no planeta, numa arquitetura hierárquica generalizada de tempo-espaço e conhecimentos sem precedentes na história: a primeira grande narrativa universal, onde a Europa é o início, o centro e a culminação da trajetória temporal. Logo, "Europa" vai ocupar uma posição privilegiada nessa arquitetura de imaginários, saberes e poderes, constituindo "uma universalidade radicalmente excludente" (LANDER, 2005, p. 10), ou seja, uma classificação arbitrária e dualista que julga "inferior" todo modelo de civilização exótico ao seu próprio. 
O pensamento eurocêntrico classifica, define e determina a métrica universal de conhecimento a partir de suas próprias particularidades, colocando-se como sujeito epistêmico consagrado ao passo que relega as demais formas de conhecimento à condição de objetos, isto é, aqueles que não se pensam; são pensados.

Outra característica do pensamento eurocêntrico é a centralidade da Europa na narrativa histórica hegemônica. Eurocentrismo é a maneira como a cosmologia europeia-ocidental institui-se imaginariamente como protagonista da história humana, reclamando para si a propriedade de determinado conjunto de valores, invenções e instituições com origens diversas que compõem o arcabouço do que conhecemos como modernidade (GOODY, 2008). Nas palavras de Nopes (2013), “o eurocentrismo é uma categoria que implica na construção de discursos, saber e a construção de um 'outro' inferiorizado para que a Europa emerja como lócus de uma enunciação na aparência universal, atópica e verdadeira; portanto, enquanto a Europa se constitui como centro emissor da história, constitui o 'outro' subalternizado" (NOPES, 2013, p. 3).

O eurocentrismo constitui a racionalidade própria da dominação colonial moderna, incidindo prerrogativa sobre a "história da humanidade", que deve tomar o padrão civilizatório ocidental (leia-se europeu e, posteriormente, estadunidense) como modelo e referência na peregrinação secular da espécie humana da "selvageria" a "civilização", em contínuo "progresso" até a "modernidade".

Segundo Dussel (2005), “o ‘eurocentrismo’ da Modernidade é exatamente a confusão entre a universalidade abstrata com a mundialidade concreta hegemonizada pela Europa como 'centro"' (DUSSEL, 2005, p. 63), tornando uma fração relativamente provinciana do continente europeu como a unidade emissora da história, o lócus da "Civilização", em detrimento do "Outro" subalternizado.

Porto-Gonçalves (2005) destaca que "é essa visão eurocêntrica que nos impedirá de ver que não há um lugar ativo, a Europa, e lugares passivos, a América, por exemplo" (PORTOGONÇALVES, 2005, p. 11), no forjar das relações sociais e da história da espécie humana. De acordo com Lander (2005), "os diferentes recursos históricos (evangelização, civilização, o fardo do homem branco, modernização, desenvolvimento, globalização) têm todos como sustento a concepção de que há um padrão civilizatório que é simultaneamente superior e normal" (LANDER, 2005, p. 36).

A modernidade é encarnada pelo pensamento eurocêntrico como uma necessidade sócio-histórica sob sua tutela. A temporalidade constituinte da história em sua concepção eurocêntrica inclui tanto o rompimento com o tempo cíclico relacionado à natureza como com o discurso das histórias como magistra vitae - mestra da vida -, modelo exemplar de conduta inspirado nos acontecimentos do passado, fenômenos não encadeados numa única (meta) narrativa histórica da humanidade. 
O padrão de poder colonial está, portanto, nos fundamentos da própria modernidade. Dito de outra maneira, a gênese do que se convencionou chamar de modernidade esteve imbricada ao colonialismo desde, ao menos, 1492 (DUSSEL, 1994) com o surgimento das rotas do atlântico e a invasão do continente americano pelos ibéricos, originando o primeiro sistema mundial da história que culminou na chamada "modernidade", ou, de acordo com Mignolo (2003), modernidade/colonialidade, indicando o lado constituinte obscurecido pelo discurso moderno. Daí a crítica à categoria mais geral de "modernidade", que seria eurocêntrica na medida em que pressupõe um processo universal concretizado sob a égide da Europa ocidental, isto é, uma categoria que exclui do campo de visão a colonialidade como processo constituinte da modernidade, considerando-a como seu antagonismo negativo, sua oposição simétrica e, logo, como apartada de si. Um imaginário dualista, eurocentrado e excludente.

\section{Colonialidade do poder/saber}

Com o colonialismo inaugurou-se uma arquitetura generalizada das relações sociais que hoje açambarca praticamente todo o planeta. Com o início da colonização "inicia-se não apenas a organização colonial do mundo, mas - simultaneamente - a constituição colonial dos saberes, das linguagens, da memória” (LANDER, 2005, p. 26).

Para Quijano (2005), “um dos eixos fundamentais desse padrão de poder é a classificação social da população mundial de acordo com a ideia de raça, uma construção mental que expressa a experiência básica da dominação colonial" (QUIJANO, 2005, p. 227). A "raça” está imbricada ao trabalho e ao gênero, numa estrutura de poder que envolve colonialismo, capitalismo e patriarcalismo (SANTOS; MENESES, 2009). O projeto civilizatório europeu fomentou o culto do "Progresso Universal", justificando o direito do capitalismo em colonizar os povos originários da denominada América, considerados "atrasados", para que também se beneficiassem dos progressos da civilização. $\mathrm{O}$ suposto atraso seria porque as sociedades denominadas primitivas são diferentes da civilizada por não disporem de deus, leis, escrita, mercado, estado e história. Essa é uma forma naturalizada, no imaginário social, de identificar o "primitivo" por meio de suas supostas ausências com relação à "civilização", um traço característico do pensamento eurocêntrico.

Nessa perspectiva, o poder é uma relação social "constituída por una trama continua de tres elementos: dominación/ explotación/ conflicto respecto del control de las áreas decisivas de la existencia social bumana" (QUIJANO, 2002, p. 50). Essas áreas são conformadas pelos seguintes âmbitos: a) o trabalho, seus recursos e produtos; b) o sexo, seus recursos e produtos; c) a autoridade coletiva, recursos e produtos; d) e a subjetividade/intersubjetividade e suas competências, especialmente o imaginário social e o modo de produção de conhecimento.

A colonialidade é compreendida como o lado obscurecido da modernidade e, logo, do colonialismo, se entendido como parte do projeto de expansão do sistema mundial. Conforme Mignolo (2003), a colonialidade do poder/saber se articula a partir das seguintes relações: a) “a classificação e reclassificação da população do planeta - o conceito de 'cultura' torna-se crucial para essa tarefa de classificar e reclassificar"; b) "uma estrutura funcional institucional 
para articular e administrar tais classificações (aparato de Estado, universidades, igreja etc.)"; c) "a definição de espaços adequados para esses objetivos"; d) "uma perspectiva epistemológica para articular o sentido e o perfil da nova matriz de poder e a partir da qual canalizar a nova produção de conhecimento" (MIGNOLO, 2003, p. 41). Segundo Wallerstein (2007), "as estruturas de saber [...] são elemento essencial do funcionamento e da legitimação das estruturas políticas, econômicas e sociais do sistema" (WALLERSTEIN, 2007, p. 94).

“A expansão ocidental posterior ao século 16 não foi apenas econômica e religiosa, mas também a expansão de formas hegemônicas de conhecimento que moldaram a própria concepção de economia e de religião. Em outras palavras, foi a expansão de um conceito 'representacional' de conhecimento e cognição [...], que se impôs como hegemonia epistêmica, política e ética" (MIGNOLO, 2003, p. 48).

Conforme Todorov (2010a), "a relação entre o saber e o poder, que pudemos observar durante a conquista, não é contingente, mas constitutiva” (TODOROV, 2010a, p. 263). A conquista foi um processo que envolveu poder e saber. Sem essas duas dimensões seria impossível a colonização das Américas.

Portanto, a colonialidade engendra-se também no conhecimento como colonialidade do saber. O conhecimento filosófico/científico se consolidou por meio da escrita que pode ser identificada a uma tecnologia de dominação historicamente reservada às elites (JEAN, 2008). No colonialismo europeu, a escrita também foi um instrumento de dominação sobre os povos ágrafos, cuja oralidade ocupava o lugar da enunciação cultural e registro da memória, ao lado de outras práticas de registro.

O problema central não é a eficácia da escrita enquanto uma técnica humana (TODOROV, 2010b), mas a eleição da escrita como método exclusivo de acesso ao conhecimento. O pensamento não depende da escrita, nem mesmo o pensamento racional. Conforme Schiwy (2002), "pensar, a pesar del legado cartesiano, no toma lugar en aislamento. Lo que sí se requiere es un contexto que le dé legitimación a esta forma de pensar" (SCHIWY, 2002, p. 123). Por outro lado, a escrita permite maior precisão no registro dos acontecimentos. O que, ao longo do tempo, pode evidentemente favorecer a elaboração, uma vez que há maior índice de referências.

O arcabouço de conhecimentos produzido sobre a matriz eurocêntrica é fundamentado nas oito línguas que compõem a “identidade imperial”: grego, latim, espanhol, português, italiano, inglês, francês e alemão. Línguas edificadoras da cosmologia ocidental. Logo, o pensamento eurocêntrico não categoriza um local geográfico, mas a "hegemonia de uma forma de pensar fundamentada no grego e no latim e nas seis línguas europeias e imperiais da modernidade; ou seja, modernidade/colonialidade" (MIGNOLO, 2008, p. 301).

\section{Colonialidade do saber e Ciências Sociais}

Wallerstein (2007) indica os três aspectos centrais da estrutura de saber do sistema mundial colonial moderno: a) sistema universitário; b) linha divisória entre as duas culturas (ciências e humanidades ou epistemologia e hermenêutica); e c) o papel especial das ciências sociais. Essa estrutura é marcada fundamentalmente pelo universalismo científico como lugar da Verdade. 
Assim, a capacidade de construção de conhecimentos considerados verdadeiros e de teorização fica restrita à autoridade filosófica/científica. Entretanto, "[...] a autoridade do último e mais poderoso dos universalismos europeus, o universalismo científico, não é mais inquestionável" (WALLERSTEIN, 2007, p. 107), abrindo margem para o questionamento do que é e a quem serve a "Teoria”, ou seja, uma expressão evidente da crise epistêmica da modernidade.

Na acepção de Connel (2012), "Teoria é o trabalho que o centro faz" (CONNEL, 2012, p. 9), sendo que a divisão social do trabalho intelectual implica uma dimensão geopolítica. Isso significa que as diretrizes de trabalho que lastreiam e fundamentam o processo de criação de conhecimento estão concentradas em instituições oriundas do Norte Global. A perspectiva da "Metrópole" é concebida para analisar uma sociedade sem determinações externas, ou seja, não considera o impacto do processo colonial, ou da colonialidade do poder/saber em sua metodologia.

Isso fica ainda mais evidente quando percebemos que os critérios de excelência para o conhecimento acadêmico são produzidos no "hemisfério norte", para onde se encaminham os/as intelectuais do Sul Global à procura de especialização. Uma vez acomodados à lógica de produção acadêmica canônica, tais intelectuais oriundos da periferia da modernidade/ colonialidade acabam se tornando "informantes da Metrópole", analisando suas realidades em abstração à sua especificidade histórica colonial ou então utilizando parâmetros universalistas em estudos comparativos para explicar e diagnosticar as falhas dos "subdesenvolvidos".

Sabemos que a expansão da racionalidade científica está imbricada à hegemonia da modernidade/colonialidade (MIGNOLO, 2003). Nesse sentido, Leff (2016) questiona:

Si entendemos la ciencia social como una construcción reflexiva sobre los hechos y los procesos sociales - como un proceso de "destilación" de la percepción y de la nominación primaria del hecho social que se configura en los imaginarios sociales, como una reflexión de segundo orden en relación con el estadio primario de la configuración de una autocomprensión de la vida, sea en la forma de un imaginario, de una cosmovisión o de una conciencia práctica -, ¿ ‘cómo habría de configurarse ese nivel de comprensión de los hechos sociales de manera que se conjugue con la autocomprensión de los propios actores sociales sobre sus procesos “internos” de construcción social? (LEFF, 2016, s/p.)

A questão evidencia o lugar dos sujeitos da enunciação científica e, logo, as redes intersubjetivas nas quais se situam e por meio das quais constroem os discursos. A subjetividade epistêmica é um dos componentes do pertencimento sociocultural dos/as cientistas sociais, envolvendo lugares de classe, gênero, étnico-culturais, epistêmicos (etc.), os quais, quando analisados a rigor, evidenciam o eurocentrismo das ciências sociais.

Noções como "história universal", "sociedade civil", "estado", "propriedade privada", "progresso", "modernidade" (entre outras) remetem a uma relação eurocêntrica com o tempoespaço, maneira de se compreender a realidade. Segundo Mignolo (2003), 
Da perspectiva epistemológica, o saber e as histórias locais europeias foram vistos como projetos globais, desde o sonho de um Orbis universalis cbristianus até a crença de Hegel em uma história universal, narrada de uma perspectiva que situa a Europa como ponto de referência e de chegada. A história universal contada por Hegel é uma história universal na qual a maioria dos atores não teve a oportunidade de ser também narradores (MIGNOLO, 2003, p. 41).

A filosofia hegeliana tende a privilegiar a lógica universalista em detrimento dos sujeitos e de suas ações sociais regulares, cotidianas. Deixando, assim, as práticas de inúmeros sujeitos de fora da narrativa universal da história.

Somente a partir desse escopo de pressupostos e abstrações foi possível surgir as Ciências Sociais como campo disciplinar, que acabaram contribuindo para estabelecer uma suposta superioridade do ocidente com base em seus "avanços" sobre o "atraso" dos seus "outros", como no caso exemplar da gênese da antropologia, uma ferramenta de dominação colonial (FABIAN, 2013). Lander (2005) afirma ainda que é com as Ciências Sociais que se dá o "processo de cientifização da sociedade liberal, sua objetivação e universalização e, portanto, sua naturalização" (LANDER, 2005, p. 35). "As categorias, conceitos e perspectivas (economia, Estado, sociedade civil, mercado, classes, etc.) se convertem, assim, não apenas em categorias universais para a análise de qualquer realidade, mas também em proposições normativas que definem o dever ser para todos os povos do planeta" (LANDER, 2005, p. 04).

Essa impressão de uma matriz única e desencarnada de conhecimento gera a sensação de um saber atemporal e atópico, espécie de verdadeiro representante da Razão Universal, como "un conocimiento antes del conocimiento" (PESÁNTEZ, 2013, p. 17-18). Conforme Grosfoguel (2007):

Se trata, entonces, de una filosofía en la que el sujeto epistémico no tiene sexualidad, género, etnia, raza, clase, espiritualidad, lengua, ni localización epistémica en ninguna relación de poder, y produce la verdad desde un monólogo interior consigo mismo, sin relación con nadie fuera de sí. Es decir, se trata de una filosofía sorda, sin rostro y sin fuerza de gravedad. El sujeto sin rostro flota por los cielos sin ser determinado por nada ni por nadie [...]. Será asumida por las ciencias humanas a partir del siglo XIX como la epistemología de la neutralidad axiológica y de la objetividad empírica del sujeto que produce conocimiento científico (GROSFOGUEL, 2007, p. 64-65).

Nas Ciências Sociais, a centralização e hierarquização do modelo de conhecimento também seguem determinados protocolos canônicos, entre os quais se inclui a "neutralidade axiológica" (WEBER, 2006), por meio do controle da relação do/a pesquisador/a com os valores morais próprios e do ambiente social em questão, isto é, da separação entre "juízo de valores" e "juízo de fatos". Para Weber (2006), o conhecimento científico atém-se aos fatos e evita avaliações de qualidade. Isso é a marca de sua "objetividade" possível, compreendida como "neutralidade axiológica", o controle das análises sobre os fatos, evitando valores, ainda que a própria escolha do tema e a articulação da problemática já indiquem, de saída, a parcialidade do/a cientista, assim como o que é considerado relevante ou não de ser pesquisado para o contexto no qual se insere. 
Conforme Cohn (2006), "sem referências a valores [na gênese da pesquisa] não se pratica ciência (pois então ela carece de interesse)" (COHN, 2006, p. 11-12). Logo, as ciências humanas e sociais, por maior que seja o esforço para aproximar-se da inteligibilidade plena sobre os fenômenos em suas análises, não são capazes de oferecer uma explicação universal e definitiva para a realidade, já que se limitam a incidir sobre aspectos parciais e finitos dessa mesma realidade, pois o número de acontecimentos é infinito no espaço e no tempo, sendo praticamente impossível de ser capturado em sua totalidade fenomênica. Conforme Weber (2006): "Não existe nenhuma análise científica puramente 'objetiva' da vida cultural, ou [...] dos 'fenômenos sociais', que seja independente de determinadas perspectivas especiais e parciais, graças às quais essas manifestações possam ser, explícita ou implicitamente, consciente ou inconscientemente, selecionadas, analisadas e organizadas na exposição, como objeto de pesquisa" (WEBER, 2006, p. 43).

Os fatos podem ser descritos como conhecimento empírico; as qualidades, como valores gerados sobre esses fatos. A observação dos fatos é sempre parcial, depende de onde se situa o sujeito do conhecimento, assim como as qualidades variam de acordo com a cultura na qual se inserem. Tanto os fatos empíricos como as qualidades culturais têm suas parcialidades. Entretanto, "De modo algum que os juízos de valor, por se basearem em última instância em determinados ideais e portanto terem origem 'subjetiva', estejam excluídos da discussão científica" (WEBER, 2006, p. 15). As "ciências da cultura", ou, ciências humanas e sociais, encarnam, em alguma medida, as qualidades culturais dos "sujeitos" da análise sobre os "objetos", isto é, dos/as pesquisadores/as sobre os acontecimentos.

Nesse sentido, podemos argumentar, com Weber (2006), que “[...] todo conhecimento reflexivo da realidade infinita realizado pelo espírito humano finito baseia-se no pressuposto tácito de que apenas um fragmento limitado dessa realidade poderá constituir de cada vez o objeto da compreensão científica" (WEBER, 2006, p. 44). Weber (2006) descreveria a ciência como uma atividade intelectual que se propõe a ordenar os fenômenos sobre os quais se debruça, estabelecendo relações lógicas e passíveis de verificação empírica entre eles num ordenamento racional da realidade. Entretanto, ressalvaria que "o domínio do trabalho científico não tem por base as conexões 'objetivas' entre as 'coisas', mas as conexões conceituais entre os problemas" (WEBER, 2006, p. 37).

Assim como Durkheim e sua concepção positivista de conhecimento sociológico por meio da análise imparcial dos fatos sociais como "coisas" (DURKHEIM, 2004), Weber também incorre no positivismo ao menos em um aspecto central da proposta da neutralidade axiológica, ainda que em outros aspectos, como nos indicados acima, indique até mesmo uma contraposição ao positivismo. Segundo Löwy (2013), "Poderia se resumir a démarche de Weber nos seguintes termos: sua teoria da Wertbeżiebung das questões [relação com os valores]é de tendência historicista; sua teoria de Wert-freiheit (neutralidade axiológica ou 'sem julgamentos de valor') das respostas é de orientação positivista” (LÖWY, 2013, p. 49).

No entanto, uma assepsia entre fato e valor é improvável na medida em que construímos parcial e situadamente nossos conhecimentos de mundo, criando análises sobre conceitos e tipos generalizadores da realidade que servem para classificarmos e explicarmos as relações sociais, dificilmente esgotando as variáveis envolvidas na complexidade de um acontecimento. 
As categorias de pensamento são aproximações, tentativas de responder às questões elaboradas, meios que permitem inteligibilidade por meio da construção de sentidos. Mas, em deslocamento ao que se propõem com frequência, esses sentidos não representam uma Razão Universal abstrata e metodologicamente manipulável. A razão é encarnada (PESÁNTEZ, 2013), isto é, exprime-se por meio de um sujeito que enuncia e cria relações a partir de uma situação, de uma trama social. Por isso tais categorias costumam não corresponder a uma "inteligibilidade unívoca" (RODRÍGUEZ, 2016, p. 124), mas a problemas situados cultural e historicamente.

Diante disso, é fundamental ater-se aos juízos dos fatos, porém sem ignorar os juízos de valores oriundos da situação epistêmica, sociocultural, ética e política do pesquisador(a), isto é, a partir de uma leitura da realidade enquanto um sujeito temporal e espacialmente situado. Conforme Leff (2016), “toda intervención en el mundo se ejerce desde su comprensión” (LEFF, 2016, s/p.).

As ciências humanas e sociais remetem-se às relações de significado e valor eleitas pelo/a observador/a, articuladas à problemática elaborada em sintonia aos interesses da pesquisa. Os/ as cientistas sociais constroem conceitos individuais por meio de tipificações e generalizações, isolando e relacionando os eventos significativos numa narrativa situada no processo histórico que não esgotam toda contingência dos acontecimentos, criando padrões de explicação e deixando lacunas do conhecimento paralelamente. Conforme Mori (2013): "Ningún acto social concreto o evento natural es descriptible completamente "en todos sus elementos individuales", ni previsible ex ante por el análisis de las circunstancias o ex post tratando de reconstruir todas las causas. Quien se empeña en la imputación causal exhaustiva sobre acontecimientos y procesos individuales asume una tarea inagotable" (MORI, 2013, p. 108).

Enquanto nas ciências naturais o debate sobre objetividade indica um "relativismo prudente", nas ciências humanas e sociais, o controle da objetividade é ainda mais precário, pois o "objeto" de análises é o próprio "sujeito" do conhecimento. Nesse campo, a subjetividade na pesquisa não é passível de controle rigoroso, seja pela imbricação entre juízo de valor e juízo de fato, seja pela impossibilidade de assepsia no julgamento, confronto ou comparação entre valores distintos. Aqui, a objetividade é mais apreensível na dimensão macrossocial, isto é, nas instituições sociais, onde há padrões maiores de regularidade em relação ao âmbito microssocial, do que em relações intersubjetivas, que exigem um esforço de compreensão maior que de explicação, ou explicação interpretativa. Logo, enquanto as ciências naturais caracterizam-se pela referência a determinações de "conexões funcionais" e de "leis" ou regras gerais, nas ciências "histórico-culturais e sociais" são fundamentais a "compreensão explicativa" e a "causalidade plena de sentido" (MORI, 2013, p. 119). A causalidade, nessa perspectiva, não se refere apenas ao "objeto", mas igualmente às representações criadas sobre ele, ou seja, ao sujeito enquanto portador do conhecimento acerca de um "objeto".

Assim disposta, a realidade não está desprovida nem de uma dimensão ontológica concreta que garante alguma efetividade objetiva do pensamento e da ação, nem de uma dimensão hermenêutica, regida pela linguagem, altamente imbricada na construção da realidade como representação ou imaginário social, isto é, praticamente inseparável - ainda que o seja para fins metodológicos. Portanto, embora não haja neutralidade na postura do/a pesquisador/a 
que observa, pensa e age de um lugar de enunciação, a partir da realidade que conhece, de sua própria experiência, é possível identificar padrões nas relações sociais, sobretudo nas instituições.

Por meio da observação dessas regularidades sociais e históricas, pode-se afirmar como essa estrutura epistemológica acima delineada institucionalizou-se como a métrica universal de fazer filosófico/científico, criando os cânones da Academia e restringido a essa instituição o poder da Verdade e, logo, excluindo uma diversa e numericamente expressiva gama de pessoas da qualidade de sujeitos de conhecimento, por não cumprirem os protocolos canônicos do pensamento eurocêntrico.

Segundo Wallerstein (2007), os pilares fundamentais do universalismo europeu assentamse no "direito dos que acreditam defender valores universais e intervir contra os bárbaros", no "particularismo essencialista do Orientalismo" e no "universalismo científico" (WALLERSTEIN, 2007, p. 109), isto é, no fardo da civilização, no etnocentrismo europeu e na fé, numa razão soberana capaz de ser enunciadora de verdades atópicas. Nessa perspectiva, o engendramento de uma "História Universal" é apresentado como um saber cuja enunciação vincula-se a uma "razão desencarnada" que nos informa a partir de algum limbo, "es decir, la razón es una entidad que se produce a si misma sin ser el producto de otra" (PESÁNTEZ, 2013, p. 15).

Os povos e grupos dominantes do que conhecemos hoje como Europa lograram êxito no processo paradoxal de estabelecerem-se como uma civilização histórica e culturalmente peculiar, excepcional, e, no entanto, com exclusiva vocação universalista. Mas como estabelecer o universal por meio do particular?

\section{Crise ou desobediência epistêmica?}

Embora a colonialidade do poder/saber resista como uma espécie de herança colonial ao deslocamento da esfera de ação direta do colonialismo após as independências nas Américas, operando como um lastro na organização das relações sociais entre as populações sob dominação colonial, a "epistemologia moderna" está em crise ao menos desde o romantismo alemão do século 19, passando pelo "martelo de Nietzsche", pela demonstração do inconsciente por Freud, pelo movimento feminista e pela diáspora pós-colonial. A emergência das vozes de sujeitos subalternizados pelo colonialismo trouxeram à tona outras experiências, olhares, imaginários e discursos. Lugares de fala anteriormente emudecidos pela estridência do universalismo cognitivo europeu passaram a conquistar espaços na esfera pública e, também, na Academia, gerando novos horizontes de pensamento outrora obscurecidos sob o monólito do pensamento eurocêntrico. Com isso, diversos campos disciplinares, incluindo as Ciências Sociais e Humanas, vêm sendo repensados e ganhando outros contornos. Conforme Ballestrin (2013), contemporaneamente,

[...] diversos autores e autoras, situados tanto nos centros quanto nas periferias da produção da geopolítica do conhecimento, questionam o universalismo etnocêntrico, o eurocentrismo teórico, o nacionalismo metodológico, o positivismo epistemológico e o neoliberalismo científico contidos no mainstream das ciências sociais. Essa busca tem informado um conjunto de elaborações denominadas Teorias e Epistemologias do Sul [...], as quais procuram valorizar e descobrir perspectivas trans-modernas, no sentido de Dussel, para a decolonização das ciências sociais (BALLESTRIN, 2013, p. 109). 
Nessa conjuntura, torna-se emergente a tarefa de criar táticas que possibilitem resistência perante a hegemonia da Metrópole criando "um modelo para uma organização global, na qual muitos mundos irão co-existir, sem serem dominados em nome de uma simplicidade e de uma reprodução de oposições binárias" (MIGNOLO, 2008, p. 319). Ressalto a co-existência, para enfatizar que um pensamento liminar, uma "epistemologia de fronteira" (MIGNOLO, 2008, p. 297) não prega a ressurreição de antigas animosidades sociais intra e internacionais, nem mesmo a fomentação de atuais; propõe-se justamente a evitar qualquer fundamentalismo, seja ocidental ou não ocidental.

Partindo disso, de que uma transformação no modelo hegemônico de se produzir e consumir teoria é não só possível como necessária, quais são as táticas possíveis para efetuar essa guinada? De acordo com Connel (2012), as mais comuns têm sido "enfatizar as distintas tradições nacionais ou estilos de trabalho intelectual” (CONNEL, 2012, p. 11); esquadrinhar sistemas originários/indígenas de conhecimento que estiveram "originalmente fora do sistema euro-centrado e que talvez ainda possa estabelecer uma base para autonomia" (CONNEL, 2012, p. 11); promover a crítica descolonial do pensamento eurocêntrico; e encontrar bases não eurocêntricas para um "universalismo alternativo".

Para isso, é necessário considerarmos um "pluralismo epistemológico” (OLIVÉ, 2009), onde se encaixam a "hermenêutica pluritópica" (MIGNOLO, 2003) e a "interculturalidade crítica" (WALSH, 2012). Mignolo (2008) afirma que, para levar tal projeto a cabo, os/as pesquisadores/as carecem de praticar a "desobediência epistêmica”, uma vez que a desobediência civil, apenas, não basta. Nesse sentido, toda transformação decolonial, decolonização política do racismo, do patriarcalismo, do racionalismo (etc.) deve suscitar desobediência civil e epistêmica.

Sem tomar essa medida e iniciar esse movimento, não será possível o desencadeamento epistêmico e, portanto, permaneceremos no domínio da oposição interna aos conceitos modernos e eurocentrados, enraizados nas categorias de conceitos gregos e latinos e nas experiências e subjetividades formadas dessas bases, tanto teológicas quanto seculares. [...] Não seremos capazes de ultrapassar os limites do Marxismo, os limites do Freudismo e Lacanismo, os limites do Foucauldianismo; ou os limites da Escola de Frankfurt, incluindo um pensador fundamentado na história dos judeus e da língua alemã tão esplêndido quanto Walter Benjamin (MIGNOLO, 2003, p. 288).

Um cuidado adicional a ser tomado é evitar a inversão dos polos da dicotomia modernidadetradição da teoria do desenvolvimento, como se pudéssemos retroceder a tempos passados criando clivagens sociais e espaciais ao longo do planeta, ou, ainda, generalizar uma "síndrome de Policarpo Quaresma" como projeto de nação. Certamente que deve haver intercâmbio entre o pensamento gerado no hemisfério norte e as preocupações do sul. Trata-se de repensar as condições sob as quais se gesta o pensamento e tomar em conta os pressupostos e possibilidades distintas que outras cosmologias, além da ocidental, podem apresentar para a pesquisa e a teorização social.

O futuro da teoria social pode ser inclusivo em vez de exclusivo. Uma pesquisa que leve em conta os complexos epistêmicos dos povos indígenas, por exemplo, deve estar focada nas transformações do conhecimento e da sociedade colonizada. Tais transformações devem 
questionar-se sobre os impactos de teorias produzidas a partir do norte e aplicadas ao sul, como no caso do neoliberalismo que, não obstante suas raízes teóricas estarem fundadas no desmonte do Estado de bem-estar social a partir dos países industrializados, foi incorporado primeiro no Chile e após em outros países que sequer chegaram a contar com um Estado de bem-estar social tal como o denominado Primeiro Mundo. São conexões a serem feitas por teorias que partam da diferença colonial. "A mudança que ocorrerá na teoria social pelo crescimento de perspectivas do Sul é, em parte, por conta do advento de novos assuntos, tais como a violência ontoformativa e a importância social da terra, mas também em parte envolve perspectivas alternativas sobre temas já existentes” (CONNEL, 2012, p. 14).

Um diálogo intercultural, decolonial, permeado por uma razão encarnada, situada, pode ser uma forma não ortodoxa de realizar a teoria em um espectro mais amplo e inclusivo, assim como proporcionar a "justiça entre saberes" como forma de ação prática contra o "epistemicídio" (SANTOS, 2017), ou seja, no sentido de valorização e preservação dos saberes subalternizados na modernidade/colonialidade.

Para isso se faz necessário uma medida de desobediência epistêmica que considere quatro aspectos: irromper com a razão colonial, com a visão eurocêntrica de "modernidade", com a ideia de que o projeto decolonial deve ser centrado na mestiçagem - categoria que generaliza a heterogeneidade "latino-americana", encobrindo formas de dominação de uma "elite crioula" - e com os limites linguísticos, uma vez que a filosofia latino-americana é bilíngue em um continente poliglota (PESÁNTEZ, 2013). Mignolo (2008) anotou a necessidade de estabelecer diálogo também a partir de línguas excluídas da cosmologia linguística da identidade imperial. Isso abriria caminho tanto para um diálogo filosófico intercultural como para uma relação de interculturalidade.

A interculturalidade deve ser entendida no contexto do pensamento e dos projetos descoloniais. Ao contrário do multiculturalismo, que foi uma invenção do Estadonacional nos EUA para conceder "cultura" enquanto mantém "epistemologia", inter-culturalidade nos Andes é um conceito introduzido por intelectuais indígenas para reivindicar direitos epistêmicos. A inter-cultura, na verdade, significa interepistemologia, um diálogo intenso que é o diálogo do futuro entre cosmologia não ocidental (aymara, afros, árabe-islâmicos, hindi, bambara, etc.) e ocidental (grego, latim, italiano, espanhol, alemão, inglês, português). Aqui você acha exatamente a razão por que a cosmologia ocidental é "uni-versal" (em suas diferenças) e imperial enquanto o pensamento e as epistemologias descoloniais tiveram que ser pluri-versais: aquilo que as línguas e as cosmologias não ocidentais tinham em comum é terem sido forçadas a lidar com a cosmologia ocidental (mais uma vez, grego, latim e línguas européias imperiais modernas e sua epistemologia) (MIGNOLO, 2008, p. 316).

Adentrar o estudo da "modernidade" a partir de uma "crítica negativa" é fundamental para decolonizar categorias explicativas arraigadas, perfazendo os caminhos históricos de sua genealogia e a crítica de seus usos.

Não são poucos/as os/as pensadores/as que consideram nossa época como um momento de transição, portanto de rupturas paradigmáticas e construção de novas relações sociais em todas as esferas, incluída a epistêmica. Carola (2010) sublinha que: “[...] a atual crise da 
“civilização global” nos impõe alguns desafios radicais. No campo da ciência, é preciso superar a racionalidade cartesiana e iluminista que se tornou parceira da ordem capitalista mundial. No âmbito da ciência histórica, é preciso inventar novos instrumentos conceituais e desenvolver um novo modo de ver, interpretar e explicar os processos históricos" (CAROLA, 2010, p. 571-572).

A tentativa de se institucionalizar uma perspectiva atópica nas ciências sociais converge com a sua desumanização, perdendo-se a noção de que as ciências são sensibilidades de mundo entre outras. Por isso, proporcionar a decolonização epistemológica das ciências sociais é fundamental para (re)humanizá-las ou, como afirma Quijano (2000), para “dar paso luego a una nueva comunicación intercultural, a un nuevo intercambio de experiencias y de significados, la mirada como la base de otra racionalidad que pueda pretender, con legitimidad, alguna universalidad" (QUIJANO, 2000, p. 447). Para tanto, é fundamental trazer à tona as lutas cognitivas entre as diferenças epistêmicas, viabilizando uma possível universalidade fundamentada na relação entre o universal e o particular da condição humana. Nas palavras de Castro-Gomes e Rivera (2002):

El término "diferencia epistémica", alude a las luchas entre posiciones hegemónicas y subalternas que tienen lugar en el interior de la cartografía geopolítica de las epistemes. Dichas luchas no son "discursivas", en el sentido adacémico de la palabra sino que, más bien, son luchas cognitivas y tienen que ver con el modo en que diferentes hombres y mujeres hacen uso de diversas formas de producir y aplicar conocimiento para relacionarse entre sí, con la naturaliza, con el territorio, con las riquezas (CASTROGOMES; RIVERA, 2002, p. 63-64).

Esse deslocamento de perspectiva é um passo fundamental para romper com a colonialidade do saber vigente. Pauta-se como uma atitude incontornável aos que vislumbram a possibilidade de fazer emergir na esfera pública saberes e práticas sociais que vão além do eurocentrismo do modus operandi das instituições sociais modernas tais como o Estado-nação, o capitalismo, a família patriarcal, a educação escolar e a academia, por exemplo. A bifurcação de perspectiva é ainda mais urgente se considerarmos que "[...] boy en día ni el materialismo histórico ni la sociología de la modernización reflexiva permiten comprender las causas, trazar los caminos y avizorar los horizontes de la historia real que burbujea en nuestro mundo en crisis civilizatoria y que late en los procesos sociales emancipatorios de los pueblos de la tierra" (LEFF, 2016, s/p.).

Construir o projeto decolonial é uma tarefa coletiva, uma proposta e um projeto comunal voltado a pensar e agir a partir da exterioridade do sistema social vigente, numa posição epistêmica que valorize os saberes subalternos, ocupando as fendas do sistema hegemônico e apresentando possibilidades outras de relações sociais, criando espaços de autodeterminação que possam agir dentro, fora e contra o sistema dominante. Nesse sentido, a opção decolonial indica uma desconstrução crítica imbuída de projetos alternativos fundamentados em valores e experiências marginalizadas pelo regime social oriundo do projeto de modernidade. 


\section{Considerações finais}

A humanidade é marcada pela pluralidade e heterogeneidade cultural e epistêmica, assim como as mesmas capacidades cognitivas. A espécie humana é única e diversa, simultaneamente. Nossa riqueza existencial consiste em nossa diversidade, em nossas formas diferentes de solucionar os problemas, de nos relacionarmos, em como escolhemos viver. A tentativa de universalização de uma tradição de pensamento, ainda que tal modelo de pensamento detenha notórios êxitos, é um ato de epistemicídio de outras tantas maneiras de entender e de se relacionar com o cosmos.

Entretanto, como podemos observar, o universalismo europeu, embora ainda hegemônico, vem sendo questionado e criticado enfaticamente por diversas categorias sociais, especialmente aquelas subalternizadas pela modernidade/colonialidade, gerando a dita crise epistêmica da modernidade. Toda crise abre precedente para a mudança. Urge ampliar os horizontes conceituais das Ciências Sociais na medida em que emergem novos sujeitos discursivos e, com eles e elas, novos olhares, estimulando a prática de um pensamento social inclusivo.

\section{Referências}

BALLESTRIN, Luciana. América Latina e o giro decolonial. Revista Brasileira de Ciência Política, n. 11, p. 89-117, maio/ago. 2013.

CAROLA, Carlos Renato. Natureza admirada, natureza devastada. História e Historiografia da colonização de Santa Catarina. Varia Historia, v. 26, n. 44, p. 547-572, 2010.

CASTRO-GOMES, Santiago; RIVERA, Oscar Guardiola. El Plan Colombia, o de cómo una história local se convierte en diseño global. In: CASTRO-GOMES, Santiago; SCHIWY, Freya; WALSH, Catherine (Orgs.). Indisciplinar las ciencias sociales: geopolíticas del conocimiento y colonialidad del poder. Perspectivas desde lo andino. Quito: Abya Yala, 2002, pp. 61-72.

COHN, Gabriel. Apresentação - o sentido da ciência. In: WEBER, Max. A “objetividade” do conhecimento nas ciências sociais. São Paulo, SP: Ática, 2006, pp. 7-13.

CONNELL, Raewyn. A iminente revolução na teoria social. Revista Brasileira de Ciências Sociais (RBCS), v. 27, n. 80, 2012.

DESCARTES René. Discurso do método; As paixões da alma; Meditações metafísicas. 5. ed. São Paulo: Nova Cultural, 1991.

DURKHEIM, Émile. As regras do método sociológico. $9^{a}$ edição. Lisboa: Editorial Presença, 2004.

DUSSEL, Enrique. 1492, el encubrimiento del otro: hacia el origen del mito de la modernidad. Mendoza: Plural Editores, 1994.

Europa, modernidade e eurocentrismo. In: LANDER, Edgardo (Org.). A colonialidade do saber. Eurocentrismo e Ciências Sociais. Perspectivas Latino-americanas. São Paulo: CLACSO, 2005, pp. 55-71.

FABIAN, Johannes. O tempo e o Outro: como a antropologia estabelece seu objeto. Petrópolis: Vozes, 2013. 
GOODY, Jack. O roubo da história: como os europeus se apropriaram das ideias e invenções do oriente. São Paulo: Contexto, 2008.

GROSFOGUEL, Ramón. Descolonizando los universalismos occidentales: el pluri-versalismo transmoderno decolonial desde Aimé Césaire hasta los zapatistas. In: CASTRO-GÓMEZ, Santiago; GROSFOGUEL, Ramon (Coords.). El giro decolonial: reflexiones para una diversidad epistemica más allá del capitalismo global. Bogotá: Siglo del Hombre Editores, 2007, pp. 62-78.

JEAN, Georges. A escrita: memória dos homens. Rio de Janeiro: Objetiva, 2008.

LANDER, Edgardo. Ciências sociais: saberes coloniais e eurocêntricos. In: LANDER, Edgardo (Org.). A colonialidade do saber. Eurocentrismo e Ciências Sociais. Perspectivas Latino-americanas. São Paulo: CLACSO, 2005, pp. 21-54.

LEFF, Enrico. Debate sobre el colonialismo intelectual y los dilemas de la teoría social latinoamericana. Cuestiones de Sociología, n. 14, 2016. Disponível em: http://www.cuestionessociologia.fahce.unlp.edu.ar/article/view/CSn14a09/7294. Acesso em: 29 nov. 2017.

LÖWY, Michael. As aventuras de Karl Marx contra o Barão de Münchhausen: marxismo e positivismo na sociologia do conhecimento. 10. ed. São Paulo: 2013.

MIGNOLO, Walter. Desobediência epistêmica: a opção descolonial e o significado de identidade em política. Cadernos de Letras da UFF - Dossiê: Literatura, língua e identidade, n. 34 , p. 287-324, 2008

Histórias locais/Projetos globais. Colonialidade, saberes subalternos e pensamento liminar. Belo Horizonte: Editora UFMG, 2003.

MORI, Luca. La noción de "evento" (ereignis) en Max Weber y las categorías lógicas de una "Ciencia del caos". Eidos: Revista de Filosofía de la Universidad del Norte, n. 18, p. 100-123, 2013.

NOPES, Adriane. Eurocentrismo e o projeto de modernização do Brasil: uma análise sociológica a partir da fala dos engenheiros professores da UFSC (1960-1980). Tese (Doutorado em Sociologia Política) - Universidade Federal de Santa Catarina, Florianópolis, 2013.

OLIVÉ, Léon. Por una auténtica interculturalidad basada en el reconocimiento de la pluralidad epistemológica. In: OLIVÉ, Léon. Pluralismo epistemológico. La Paz: CLACSO/ CIDES-UMSA, 2009, pp. 19-30.

PESÁNTEZ, Catalina León. El color de la razón: pensamiento crítico em las Américas. Quito: Universidad Andina Simón Bolívar, 2013.

PLATÃO. República. Rio de Janeiro: Editora Best Seller, 2002.

PORTO-GONÇALVES, Carlos Walter. Apresentação da edição em português. In: LANDER, Edgardo (Org.). A colonialidade do saber. Eurocentrismo e Ciências Sociais. Perspectivas Latino-americanas. São Paulo: CLACSO, 2005, pp. 09-16.

QUIJANO, Aníbal. Colonialidade do poder, eurocentrismo e américa latina. In: LANDER, Edgardo (org.). A colonialidade do saber. Eurocentrismo e Ciências Sociais. Perspectivas Latino-americanas. São Paulo: CLACSO, 2005, pp. 227-278. 
El regresso del futuro y las cuestiones de conocimiento. In: CASTRO-GOMES, Santiago; SCHIWY, Freya; WALSH, Catherine (Orgs.). Indisciplinar las ciencias sociales: geopolíticas del conocimiento y colonialidad del poder. Perspectivas desde lo andino. Quito: Abya Yala, 2002, pp. 45-60.

RODRÍGUEZ, Carlos Juan Núñez. Genealogia del Estado desde América Latina: la invención del Estado nación. Ciudad de México: Universidad Nacional Autónoma de México, 2016.

SANTOS, Boaventura de Sousa; MENESES, Maria Paula. Introdução. In: SANTOS, Boaventura de Sousa; MENESES, Maria Paula (Orgs.). Epistemologias do Sul. Coimbra: Edições Almedina, 2009, pp. 9-21.

SANTOS, Boaventura de Sousa. Justicia entre Saberes: Epistemologías del Sur contra el epistemicidio. Madrid: Morata, 2017.

SCHIWY, Freya. Intelectuales subalternos?: notas sobre las dificuldades de pensar en diálogo intercultural. In: CASTRO-GOMES, Santiago; SCHIWY, Freya; WALSH, Catherine (Orgs.). Indisciplinar las ciencias sociales: geopolíticas del conocimiento y colonialidad del poder. Perspectivas desde lo andino. Quito: Abya Yala, 2002, pp. 103-134.

TODOROV, Tzvetan. A conquista da América: a questão do outro. 4. ed. São Paulo: Martins Fontes, 2010a.

. O medo dos bárbaros: para além do choque das civilizações. Petrópolis: Vozes, 2010b.

WALLERSTEIN, Immanuel. O universalismo europeu: a retórica do poder. São Paulo: Boitempo, 2007.

WALSH, Catherine. Interculturalidad crítica y (de)colonialidad: ensaios desde Abya Yala. Quito: Ediciones Abya Yala, 2012.

WEBER, Max. A “objetividade” do conhecimento nas ciências sociais. São Paulo: Ática, 2006. 